\title{
A constituição do menemismo na província de Buenos Aires
}

Em 9 de julho de 1988, pela primeira vez em sua história o peronismo elegeu os candidatos a presidente e vice-presidente da República por voto direto dos filiados, tomando o país como distrito único ${ }^{1}$. Essas eleições internas, dirimidas entre representantes da corrente renovadora do partido, consagraram a candidatura de Carlos Menem - Eduardo Duhalde frente à que era composta por Antonio Cafiero - José Manuel de la Sota ${ }^{2}$. O resultado provocou certa perplexidade. Cafiero era presidente do Conselho Nacional Justicialista e do Partido Justicialista Bonaerense (PJB), além de governador da província de Buenos Aires. Caía ante o vice-presidente do partido, governador de La Rioja, que com ousadia manifestou seu desejo de ser presidente da Nação praticamente desde a recuperação democrática e que, enquanto ocupava espaços centrais dentro do aparato partidário, cultivava uma imagem de condutor político antissistema.

As interpretações desse momento constitutivo do menemismo - mesmo em âmbito nacional - foram relativamente esquivadas pelas ciências sociais se comparadas com a fascinação manifestada ao explicar a ascensão de Menem à presidência da República, a virada neoliberal adotada por seu governo, as

\footnotetext{
* Professora da Universidad Nacional de Mar del Plata (Mar del Plata, Argentina) e pesquisadora do Consejo Nacional de Investigaciones Científicas y Técnicas (CONICET).E-mail: marcelapatriciaferrari@gmail.com

1 Entre 1946 e 1973 as chapas presidenciais haviam sido designadas pelo fundador do movimento, Juan Domingo Perón. Em 1983 a dupla Luder Bittel foi definida pelo Congresso Nacional Justicialista. Entre outros, cf. El Independiente (El), La Rioja, 9/7/1988.

2 Uma terceira chapa, muito minoritária, foi encabeçada pelo correntino Julio Romero.
} 
adesões que obteve ou as mudanças na identidade peronista ${ }^{3}$. Mas existem alguns trabalhos que o analisaram sob a luz das origens, das condições e dos limites da renovação. Assim, Arias identifica o sucesso do menemismo como resultado da heterogeneidade da própria corrente, que foi efetiva na hora de instaurar uma nova metodologia de seleção de candidatos por meio de eleições primárias por voto direto dos filiados e de incorporar dirigentes jovens, mas que nunca conseguiu superar as diferenças internas, institucionalizar valores capazes de produzir uma genuína mudança doutrinária, nem erradicar o personalismo (Arias, 2004) ${ }^{4}$.

Esta explicação contribui para desmontar a representação quase exclusiva da renovação como corrente rupturista, inovadora e moderna que, em grande medida, promoveram seus protagonistas - especialmente os setores cafieristas e de centro-esquerda - para diferenciar-se daqueles aos quais haviam qualificado como ortodoxos da direita peronista, seja vindos do ramo sindical, seja vinculados a ele $^{5}$. Com efeito, dentro desse enorme leque que é o peronismo, estendido entre a direita e a esquerda do arco ideológico e entre a parte de cima e a de baixo da hierarquia social (Ostiguy, 1997), os opositores da cúpula que perdeu as eleições de 1983 aglutinaram-se a partir do início de 1985 sob a denominação comum de renovadores. Alguns membros deste grupo, que se autorrepresentavam como modernizadores sem renunciar à tradição, estigmatizaram como ortodoxos os integrantes da

\footnotetext{
Algumas dessas preocupações, que tratam de soslaio o final dos anos 80 e a construção do menemismo, referem-se ao caráter populista da condução a partir das transformações operadas nos regimes de acumulação e de governo (Nun, 1995), as consequências da crise econômico-financeira (Gerchunoff e Torre, 1996), as práticas de cooptação de dirigentes (Portantiero, 1995; Mora y Araujo, 1995), a emergência de líderes em um contexto de crise de representação (Novaro, 1994). O peronismo desses anos também tem sido observado sob a luz das respostas que ofereceu este partido flexível e pouco rotinizado às consequências dos processos de desindustrialização e dessindicalização que teriam debilitado as bases sociais tradicionais do movimento, levando-o a privilegiar formas territoriais e clientelares de construção de poder (Levitzky, 2005). A inscrição do menemismo no processo nacional pode ser encontrada em Palermo e Novaro (1996) e Novaro (2006; 2009). Uma amostra atualizada das interpretações do menemismo que privilegia o ponto de vista da identidade e recupera boa parte das contribuições realizadas para explicar o fenômeno, pode ser vista em Gouarnalusse (2011).

${ }^{4}$ Corresponde esclarecer que, enquanto a renovação foi dominante na condução justicialista, a seleção de dirigentes combinou o voto direto para eleger autoridades partidárias, candidatos a legisladores, autoridades municipais e para presidente e vice-presidente da República, com eleições indiretas de candidatos a governador e vice e parlamentares, responsabilidade que cabia ao congresso de distrito. Sobre o discurso cafierista e da centro-esquerda (Altamirano, 2004). As posições ocupadas no peronismo, à esquerda ou à direita do espectro político e acima e abaixo do arco social são estudadas em Ostiguy (1997). Neste texto, as referências à ortodoxia e à direita são tomadas no sentido em que eram interpretadas pelos contemporâneos.
} 
direita e da extrema direita do movimento, nutrida fundamentalmente pelos grandes sindicatos integrados nas 62 Organizações Peronistas ou por grupos vinculados a elas, que se amparavam na simbologia e na verticalidade do movimento e faziam uso político de práticas de pressão sobre o adversário, as quais não excluíam a intimidação física. Contudo, entre os renovadores havia alguns que estavam muito próximos dos ortodoxos, com os quais compartilhavam tradição, identidade e simbologia, mas que, com o senso de oportunidade que dava a necessidade de se diferenciar dos derrotados, não renunciavam a se apresentar sob denominação protetora da renovação, mesmo que sua trajetória fosse mais próxima da ortodoxia que daquilo que o termo representa ${ }^{6}$.

Certamente, o conjunto da renovação remoçou o partido e introduziu alguns princípios básicos, tais como a defesa da democracia partidária e o voto direto como critério de seleção de candidatos de governo e de dirigentes partidários. Mas, fora isso, não existiam muitos elementos que amalgamassem um heterogêneo conjunto no qual alguns políticos representativos dos setores intelectuais de centro-esquerda que propunham uma mudança profunda de práticas consideradas retardatárias alternavam-se com outros moderados, com sindicalistas que tinham combatido o regime militar e, também, com caudilhos tradicionais que, com resultados muito bons, utilizavam práticas de construção de poder fortemente personalistas (Ferrari, 2011).

São estas interpretações que tornam possível explicar o triunfo do menemismo sob a luz das condições da renovação que o gerou. No caso bonaerense, é possível sustentar que o setor cafierista foi capaz de alcançar o controle do partido, mas não de formalizar e rotinizar seu poder, parafraseando Levitzky (2005). Por essa razão, não conseguiu se impor sobre o conjunto dos dirigentes nem sobre a maioria dos filiados. Devido a isso, não conseguiu resistir a investida interna de uma força que se apresentava recuperando bandeiras tradicionais do peronismo, nem sequer ali onde seu líder, além de ser presidente do Conselho Nacional partidário, era titular do conselho provincial e governador da província.

Nessa linha, este trabalho apresenta explicações para compreender de que maneira uma seleção de candidatos orientada por critérios democráticos,

As denominações "renovadores" e "ortodoxos" são utilizadas aqui, seguindo Pierre Bourdieu, como "categorias da prática", ou seja, tomadas da experiência social cotidiana dos próprios agentes. Cf. Bourdieu (1991). 
que nas projeções dos seguidores de Cafiero devia derivar no afastamento definitivo dos ortodoxos, desembocou em sua reinstauração. E faz isso reconstruindo o progressivo avanço do menemismo na província de Buenos Aires no médio prazo, entre sua chegada em janeiro de 1986 e julho de 1988, momento em que foi definida a candidatura presidencial. Em primeiro lugar, sintetiza a performance obtida nas eleições destinadas a selecionar autoridades partidárias e candidatos a cargos governamentais. Depois, é feita uma aproximação aos motivos dessa progressão eleitoral, a qual coloca a ênfase nos atores políticos e nas práticas utilizadas no que se refere a: (a) cooptação concertada de dirigentes políticos ${ }^{7}$, que derivou na construção de uma rede política capaz de mobilizar a adesão dos filiados de base; (b) uso instrumental de aspectos formais inerentes ao processo eleitoral, que teriam permitido ao menemismo prolongar os tempos do cronograma eleitoral e separar a seleção da chapa presidencial do resto, para fraturar o aparato partidário; e (c) campanha pré-eleitoral, na qual foi difundida uma representação do menemismo como autêntico peronismo - popular, personalista, em contato com as massas, capaz de reivindicar seus mitos - que, a partir de uma dimensão simbólica, incidiu positivamente nos filiados em tempos de uma profunda crise político-social atribuída ao governo nacional, do qual o cafierismo era visto como próximo demais.

Este processo somente é possível de ser compreendido se forem postas em jogo diferentes escalas analíticas (Revel, 1996) dadas a forte imbricação política da província no país (Ollier, 2010), as características deste partido nacional de distrito e a relação permanente estabelecida entre dirigentes dos âmbitos nacional, provincial e municipal.

\section{Entre um desembarque desvantajoso e a candidatura presidencial}

Em fevereiro de 1986, em um ato proselitista realizado em Mar del Plata, que foi presidido pelos três nomes referenciais da corrente renovadora - Antonio Cafiero, Carlos Grosso e Carlos Menem -, apareceram entre os

Ivancich, referindo-se ao processo em estudo, definiu cooptação como "a capacidade de um grupo de selecionar aquele que vai incorporar em seu seio e mantê-lo controlado dentro das linhas do próprio grupo, para que eles não provoquem modificações substanciais"(Ivancich, 2004, p. 36). Em um sentido similar expressam-se Portantiero (1995) e Mora y Araujo (1995). Entendo que esse comportamento reduz os cooptados a uma atitude passiva, com a qual não concordo. Opto por utilizar a noção de cooptação concertada, uma vez que expressa a vontade e os interesses dos indivíduos que aceitam se integrar em um espaço político em virtude da obtenção de algum benefício, material ou simbólico. 
participantes cartazes da Coordenadora "Menem Presidente" (La Nación (LN), 23/2/1986). Isso ocorreu apenas três meses após as eleições legislativas em que o justicialismo se apresentou dividido entre o FREJUDEPA - uma aliança entre os dissidentes renovadores, a Democracia Cristã e o Partido Conservador Popular - e o FREJULI, organizado pelo ex-intendente de Avellaneda e candidato a governador provincial pelo PJB em 1983, Herminio Iglesias, que reunia o setor ortodoxo do peronismo, com forte representação dos grandes sindicatos controlados pelo peronismo, e do MID. Nessa ocasião, a UCR triunfou na eleição, mas os seguidores de Cafiero obtiveram $27 \%$ dos votos, diante dos $10 \%$ alcançados pelos seus adversários internos. O triunfo interno alentou a consolidação da corrente renovadora, que desde 1984 se perfilava com força dentro do espectro partidário. Seu lançamento foi concretizado em dezembro de $1985^{\circ}$. Que um dos referenciais eleitos dessa corrente, apenas dois meses antes de que fosse levado a público o documento fundacional, lançasse sua candidatura sem prévia consulta, agudizava as tensões do conjunto.

Em maio, "Federalismo e Liberação" (FyL) - tal era o nome da agrupação organizada pelo governador riojano -, anunciaram que essa candidatura seria lançada oficialmente em julho, em uma plenária a ser realizada na cidade de Cosquín (LN, 12/5/1986) ${ }^{9}$. No mesmo mês, a agrupação desembarcou oficialmente na província de Buenos Aires, contando com reduzidos apoios: o de um setor do sindicalismo encabeçado pelo gastronômico Luis Barrionuevo e o de um punhado de políticos que estavam em torno de Juan Carlos Rousselot, futuro intendente de Morón ${ }^{10}$. Seu propósito era ampliar as bases de sustentação da agrupação e, após eleições internas, controlar espaços que lhe permitissem enfrentar desde o interior do distrito mais importante do país a disputa pela candidatura presidencial.

Até julho de 1988, avanços progressivos apareceram em cada convocatória eleitoral interna. A primeira foi a de novembro de 1986. Em abril desse ano o

\footnotetext{
As origens da renovação inscrevem-se em um processo iniciado após o fracasso eleitoral de outubro de 1983. Sobre a primeira organização na Frente Renovadora Peronista de dezembro de 1984, ver Mc Adam (1996, p. 124). Sobre os congressos que derivaram na formação da renovação, ver Ivancich (2004). O curso da reorganização partidária em Buenos Aires é apresentado em Ferrari (2010; 2011). Sobre a fundação da corrente, cf. "Documento fundacional da Renovação Peronista" em Cafiero (2007, p. 103-112).

A plenária ocorreu em Cosquín entre os dias 4 e 6 de julho (LN, 3 e 7/7/1986).

10 Algumas fontes orais assinalam também o apoio de um meio de imprensa como Ámbito Financiero (da entrevista a Eduardo Benedetti, Buenos Aires, 5/8/2010).
} 
PJB sofreu uma intervenção que visava alcançar sua normalização pela via de eleições de autoridades partidárias e de candidatos a ocupar cargos eletivos municipais, provinciais (governador e legisladores) e nacionais (deputados), adiante da convocatória aberta de setembro de 1987. Na época, a província era o bastião da renovação cafierista. Consciente disso, o objetivo de $\mathrm{Me}$ nem era mínimo: se conseguisse obter os votos suficientes para introduzir uma minoria no conselho partidário bonaerense e $10 \%$ dos congressistas nacionais do distrito, poderia fazer as alianças necessárias para impor o voto direto considerando o país como distrito único na hora de escolher a chapa de candidatos para a presidência da Nação. Ou seja, Federalismo e Liberação não iam disputar a candidatura para governador. Pelo contrário, respaldava Cafiero, apesar de ter apresentado uma lista "diferente daquela da Frente Renovadora", sem renúncia de seu mentor a ser presidente do partido e com a condição de que Cafiero vencesse na primeira seção eleitoral (LN, 1 e 31/8/1986).

A ressentida relação de FyL com a Frente Renovadora rompeu-se quando concorreu ao congresso nacional partidário de Tucumán (novembro de 1986), ao qual a direção renovadora tinha decidido não assistir. Ali, Menem obteve garantias do presidente do Conselho Nacional Justicialista, Vicente L. Saadi, de que o candidato à presidência da Nação pelo justicialismo seria escolhido por voto direto dos filiados, tomando o país como distrito único (LN, 5/11/1986) $)^{11}$.

Chegado o dia das assembleias para eleger as autoridades partidárias do justicialismo bonaerense (16/11/1986), FyL apresentou-se como Lista 400. Contava com candidatos em 7 das 8 seções eleitorais do distrito. Votaram 36\% do justicialistas registrados. Dessa porcentagem, a Frente obteve $60 \%$ dos votos e ganhou em todas as seções. FyL conseguiu a representação minoritária no conselho provincial justicialista: Juan Carlos Rousselot, José Díaz Bancalari, Manuel Quindimil e Luis Echeverría, pelas seções 1, 2, 3 e 7, respectivamente, e cobriu o $10 \%$ dos representantes que a lista havia se proposto posicionar no Congresso Nacional (LN, 18/11/1986; El Día (ED), 18/11/1986).

Ficava pendente selecionar os candidatos para cargos eletivos (governador e vice e deputados nacionais), por eleição indireta do congresso partidário provincial em 10/1/1987. FyL tinha minoria nesse congresso. Como estava

${ }^{11}$ A tensão com o Conselho Nacional, na entrevista a C. Grosso, cit. 
previsto, apoiou a chapa Cafiero-Macaya e conseguiu para José María Díaz Bancalari, de San Nicolás, o $9^{\circ}$ lugar na chapa de candidatos a deputados nacionais encabeçada por Eduardo Duhalde, que negociou essa posição depois de renunciar a fazer parte da chapa no segundo lugar (ED, 11/1/1987) ${ }^{12}$.

Em 26 de abril de 1987 os filiados peronistas bonaerenses foram convocados novamente para escolher por voto direto (art. 17 da Carta Orgânica) os candidatos a legisladores provinciais, intendentes, vereadores e conselheiros escolares (Art. 17 da Carta Orgânica). Ali era preciso operar na ordem municipal, e Menem declarou sua intenção de favorecer a formação de listas de unidade, salvo quando as situações nos distritos fossem inconciliáveis (ED, 10/3/1987). La Plata foi um dos casos em que os dirigentes se dividiam ou se reagrupavam movidos pela ânsia de ocupar posições de poder ou em função de relações pessoais, mais do que por enfrentamentos programáticos.

$\mathrm{Na}$ capital da província, a lista que havia sustentado o cafierismo nas eleições de novembro de 1986 se dividiu. De fato, um setor da lista Branca 91, encabeçado por dois conselheiros partidários provinciais, Enrique Cano e Luis Lugones, rompeu com o tronco partidário. Aproximou-se da Frente de Renovação e Unidade Peronista, FRUP, que respondia ao jovem dirigente Julio Alak e à FyL ${ }^{13}$. Juntos, os dirigentes das listas 91, 10 e 400 compuseram outra, identificada com a soma dos três números: a Lista 501, que se autodenominou "Unidade e Renovação". O nome recuperava o da agrupação que pouco antes tinham organizado na $3^{\text {a }}$ seção eleitoral os intendentes renovadores Eduardo Duhalde, de Lomas de Zamora, e Julio Carpinetti, de Florencio Varela. Os resultados desse processo eleitoral, atravessado pela crise militar da Semana Santa de 1987, deram um apertado triunfo à lista de unidade no peronismo platense nas eleições de 26 de abril. Carlos D’Agostino, integrante de FyL obteve a postulação como candidato a primeiro senador provincial pela seção capital. Em La Plata participaram 30\% dos filiados, superando muito a média provincial de 17\% (ED, 28/4/1987).

Ou seja, o menemismo estava conseguindo posições expectáveis no interior do PJB e candidaturas para postos de governo. Além de D’Agostino, Juan Carlos Rousselot foi eleito candidato a intendente em Morón. Os ex-

\footnotetext{
12 Uma vez que as listas foram apresentadas, no mês de julho, Eduardo Duhalde foi relegado ao segundo lugar e Díaz Bancalari ao décimo primeiro (ED, 19/7/1987).

13 Sobre a reunião de Cafiero com os dissidentes, ED 20 e 21/3/1987. Sobre Federalismo e Liberação, ED, 18/1 e 7/2/1987.
} 
-herministas decididos a apoiar listas de unidade, Manuel Quindimil e Federico Russo, continuaram controlando Lanús e La Matanza respectivamente. Hugo Toledo, homem de Duhalde, conseguiu postular-se como intendente de Lomas de Zamora (ED, 28/4/1987).

Superada essa instância, "o conflito interno do justicialismo ficou congelado até 6 de setembro" (ED, 3/5/1987) quando A. Cafiero e L. Macaya foram eleitos governador e vice da província. Os peronistas compreendiam muito bem uma situação que Cafiero sintetizou em uma de suas visitas de campanha a La Matanza, quanto a "fazer um pacto de amizade dentro de um marco de companheirismo (para) salvar o peronismo, porque se não conseguirmos a união da Província, o fantasma da dispersão peronista voltará a se apresentar" (ED, 17/6/1987). Um reflexo desse clima de convivência foi a unificação dos blocos justicialistas em ambas as Câmaras da Legislatura bonaerense (ED, 20/6/1987).

Contudo as apostas políticas continuaram. Houve algumas diferenças internas em âmbito local, em que proliferavam agrupações que se desprendiam do tronco partidário quando os resultados eram desfavoráveis para eles $^{14}$. Em âmbito nacional, as mais evidentes eram as dos grandes sindicatos nucleados no "Grupo dos 15", que além de aceitarem o oferecimento do governo nacional de levar um de seus membros, Luis Alderete, para o Ministério do Trabalho, aspiravam a eliminar Cafiero da corrida presidencial (ED 13/7/1987). Mas se alguém fez uma jogada forte foi o próprio A. Cafiero, quando alterou a decisão adotada pelo congresso provincial. Em meados de julho foram publicadas as listas definitivas de candidatos do PJB. A de deputados nacionais era encabeçada por Italo Luder, e E. Duhalde ficou relegado ao segundo lugar. $\mathrm{O}$ fundamento era que o primeiro atrairia votos independentes, dada a sua condição de advogado constitucionalista, em tempos em que era discutida uma possível reforma constitucional. A surpresa foi grande, especialmente para o relegado, que tomou conhecimento da notícia pelos jornais (ED, 19/7/1987) ${ }^{15}$. O fato, como será visto, trouxe consequências importantes na disputa entre cafieristas e menemistas.

\footnotetext{
${ }^{14}$ Em Florencio Varela formaram-se três agrupações vicinais lideradas por opositores a Julio Carpinetti, que os havia derrotado nas internas como candidato a intendente. Os poucos fieis a Herminio Iglesias organizaram o partido "17 de Outubro", que em pouco tempo foi impugnado pelos renovadores por apropriar-se de um símbolo da identidade justicialista (ED, 11/6/1987).

15 Díaz Bancalari foi deslocado do 90 para o 11 l lugar. Sobre essa "traição" de Cafiero, ver López López Echagüe (2002).
} 
Apesar de tudo, até as eleições gerais todos os esforços dos peronistas confluíram, honrando a máxima partidária que diz que quem ganha conduz e quem perde, acompanha ${ }^{16}$. No dia 6 de setembro de 1987 o peronismo obteve uma clara vitória na província ${ }^{17}$ e, dentro do espectro peronista, os candidatos de FyL, sempre em franca minoria, conseguiram firmar-se em cargos de governo. A imprensa contabilizava para esta linha interna grandes distritos do conurbano, como Lanús, La Matanza e Morón, além de cargos legislativos e parlamentares (ED, 27/12/1987).

Passada essa instância eleitoral, Menem reafirmou seu velho anelo de ser presidente do partido e candidato presidencial em $1989^{18} \mathrm{e}$ impulsionou com força a consolidação de sua corrente dentro do partido ${ }^{19}$. Em âmbito nacional, era preciso eleger a direção que substituiria a encabeçada por Saadi desde julho de 1985, no congresso de La Pampa. Foi organizada uma lista única, razão pela qual não foi necessário convocar eleições ${ }^{20}$. Apesar das aspirações do governador riojano, a condução do CNJ ficou encabeçada por Cafiero e Menem foi nomeado vice-presidente.

Para diminuir a importância desse fato, um dia antes de eleger as autoridades partidárias foi lançada a corrente "Menem presidente de todos os argentinos" em um ato do peronismo metropolitano organizado pelo dirigente ortodoxo Julián Licastro. Nessa ocasião, o pré-candidato expressou

16 Sobre a campanha, o debate televisivo entre Cafiero e o candidato radical Casella (28/8/1987) ou a "caravana da esperança" de Cafiero, que percorreu partidos da GBA, de Tigre até Avellaneda, ver ED, 28/8/1987 e 30/8/1987.

17 Foi uma vitória em um marco triunfalista: 17 das 22 províncias ficaram em mãos de governadores justicialistas.

18 Em 10 de setembro, a Capital Federal amanheceu coberta de cartazes com a legenda "Agora Menem presidente" que, ambiguamente, apontavam para a presidência do partido e para a da Nação (ED, 11/9/1987).

19 Inaugurou locais partidários inclusive em povoados do interior. O caso de San Juan está presente em $\mathrm{ED}, 12 / 10 / 1987$.

${ }^{20}$ O processo não esteve isento de tensões. Saadi queria uma "saída digna", sem as críticas dos renovadores. As negociações mantidas nesse sentido foram conduzidas por seu representante, Julio Mera Figueroa e, do lado da renovação, José Luis Manzano, José Manuel de la Sota e Olga Ruitort (ED, 21 e 22/10/1987). Também o ramo sindical foi cenário de controvérsias que ameaçaram dificultar a transferência da direção do movimento para os renovadores. A crise desencadeou-se na CGT e colocou em questão a liderança ubaldinista. O pano de fundo era o deslocamento dos grandes grêmios peronistas "ortodoxos" das posições de condução na central operária e nas listas de candidatos, que em um caso favorecia os ubaldinistas e, no outro, o sindicalismo renovador.Ver ED, outubro-novembro 1987, passim. O congresso nacional justicialista aprovou a caducidade das autoridades partidárias, designou um conselho provisório integrado por governadores eleitos e chefes de 21 distritos, fixou o prazo para a apresentação de listas para 30 de dezembro de 1987 e convocou eleições internas nacionais para o dia 6 de março de 1988, o que não foi necessário dada a formação de uma lista única. ED, 30/11/1987. 
que tentaria "neutralizar eventuais arranjos de cúpulas ou aparatos que pretendam desconhecer o clamor popular e a forma de canalização já instituída por eleições diretas com distrito único" (ED, 30/12/1987). Daí em adiante, essa representação da interna peronista que identificava o menemismo como expressão dos setores populares em luta contra o aparato partidário foi bastante explorada ${ }^{21}$. A capacidade do pré-candidato de vincular-se diretamente com o povo não fez outra coisa senão reforçar essa identificação. Apesar da insistência de muitos dirigentes de âmbito nacional, principalmente das 62 Organizações, favoráveis a uma chapa de unidade Cafiero-Menem, ficou claro que o vice-presidente do PJ não se subordinaria como, segundo declarava, tinha feito ao renunciar à titularidade do partido. Não legitimava, assim, o consenso com o qual havia contado Cafiero (ED, 19/3/1988; 11/1/1988).

Em fevereiro de 1988 foi lançada a pré-candidatura de Cafiero para a presidência da Nação no campo de esportes da Associação Judiciária Bonaerense ${ }^{22}$. Após algumas discussões, a pré-candidatura de De la Sota para a vice-presidência foi decidida no início de março (ED, 8/3/1988). De um ponto de vista federalista, ele ser de Córdoba contrabalançava o "portenhismo" de Cafiero. Era um renovador da primeira hora, que gerava adesões e rejeições como integrante do grupo conhecido como "os jovens turcos" integrado também por Grosso e Manzano - destacado por sua tentativa de levar a renovação até as suas últimas consequências, rompendo lanças com a ortodoxia. Seus ataques a esse setor romperam o equilíbrio da representação por ramos pretendida pelas 62 Organizações que apoiavam José Luis Vernet para ocupar a segunda vaga da chapa. De la Sota nunca mediu suas investidas e até o último momento atacou a "turma" sindical, algo que lhe valeu o rancor do muito influente Lorenzo $\mathrm{Miguel}^{23}$.

Enquanto na Frente Renovadora se discutia o segundo nome da chapa, Menem apressou-se em oferecer a Eduardo Duhalde que fosse seu segundo (ED, 10/2/1988). O gesto apontava na direção de obter "peso político" na província

\footnotetext{
${ }^{21}$ Essa construção foi sustentada ao longo de todo o período pré-eleitoral. No dia da eleição, o jornal riojano El Independiente publicava as fotografias de ambos os candidatos, ao pé das quais afirmava "CAFIERO: com o apoio do 'aparato"' e"MENEM: com as bandeiras do federalismo", em um meio onde federal é sinônimo de popular (El, 9/7/1988).

22 A escolha do lugar aprofundou o rancor das 62 Organizações, que questionaram a celebração em um lugar pertencente a uma organização sindical "de reconhecida tendência comunista", escolhido pelos 25 (ED, 8/3/1988).

${ }^{23}$ R. West Ocampo, "¿Fractura en el peronismo?", em ED, 10/3/1988, p. 5. A nota inclui uma avaliação sobre as alternativas para completar o binômio encabeçado por Cafiero.
} 
que definiria as eleições internas, dado que contava com um terço dos filiados peronistas de toda a República. Inicialmente, Duhalde não se definiu. Reiterou seu apoio à pré-candidatura de Menem argumentando que Cafiero, pela primeira vez, "não está interpretando o sentimento das bases" e reafirmou seu desejo de que a chapa presidencial do justicialismo fosse encabeçada por quem obtivesse a maior quantidade de votos na eleição interna, secundado por quem ficasse em segundo lugar. Mas não descartou a pré-candidatura se assim "fosse decidido pelo condutor" que "conta com o apoio da maioria absoluta dos filiados justicialistas da província de Buenos Aires" (ED, 13/2/1988). Uma e outra vez o dirigente de Lomas de Zamora prognosticou a avalanche de votos que daria a vitória a Carlos Menem. Aceitou sua candidatura só em março (ED, 5/3/1988). O pertencimento dos dois integrantes da chapa à Renovação era tão indiscutível quanto os motivos de ambos para enfrentarem Cafiero (ED, 10/3/1988).

As eleições de 9 de julho de 1988 puseram em evidência a grande conquista do conjunto da renovação: tratou-se de uma demonstração de que o peronismo era capaz de selecionar candidaturas de maneira democrática. A disciplina e o comportamento dos filiados mereceram o reconhecimento de próprios e alheios (ED, 10/7/1988). O triunfo correspondeu à chapa Menem-Duhalde. Na província de Buenos Aires venceram seus adversários internos por quase 40.000 votos (ED, 13/7/1988).

Tornou-se evidente que o mapa do peronismo provincial tinha mudado (ED, 14/7/1988). Como era de se prever, o voto na GBA marcou a diferença ${ }^{24}$. $\mathrm{Na} 3^{\text {a }}$ seção eleitoral o menemismo venceu em 14 dos 17 distritos. O cafierismo ficou com Ensenada e Lobos, enquanto Avellaneda - 4 dias antes das eleições - continuava em litígio. Chamaram a atenção La Matanza e Lanús, lugares em que os resultados contrariaram as orientações de seus intendentes. Em La Matanza, Menem obteve quase 27.000 votos, contra 17.000 de Cafiero, e em Lanús, seus votos praticamente dobraram os de Cafiero - 10.700 contra 5.400. Houve o dobro de votos a favor de Menem em Lomas de Zamora (18.000 a 9000), um resultado esperado no território do grande armador do justicialismo bonaerense: Eduardo Duhalde. O menemismo triunfou também em Florencio Varela, Quilmes, Almirante Brown, Berazategui, Esteban Echeverría, San Vicente, Berisso, Cañuelas, Brandsen e Magdalena.

\footnotetext{
${ }^{24}$ Apesar de não contar com informação direta sobre a quantidade de filiados peronistas nas seções, tem-se um indicador sobre a representatividade de ambas as seções no registro do ano anterior. Ali se concentrava 66\% do eleitorado provincial. Província de Buenos Aires. Direção provincial de estatística, Subsecretaria da Fazenda http://www.ec.gba.gov.ar/Estadistica/Ftp/index.html
} 
Na $1^{\text {a }}$ seção, segunda em quantidade de votos justicialistas, o cafierismo venceu em apenas dois municípios do conurbano: San Isidro e San Fernando, e em outros cinco fora dessa zona: Campana, Mercedes, Las Heras, Suipacha e Navarro. O menemismo triunfou em Morón, San Martín, Merlo, General Sarmiento, Moreno, Três de Febrero, Pilar, Vicente López, Escobar, Marcos Paz, General Rodríguez, Luján e Tigre. No resto da província os resultados foram mais benignos para Cafiero-De la Sota, mas as diferenças não compensaram a derrota na GBA. Na 2a , Menem e Duhalde triunfaram em dois distritos importantes: Pergamino e San Nicolás e, na 4a , em Pehuajó e Trenque Lauquen. $\mathrm{Na} 5^{\text {a }}$, Cafiero ganhou em Partido de la Costa e em Gral. Pueyrredón. Na $6^{\mathrm{a}}$, a maioria também foi para o governador bonaerense, apesar das vitórias de Menem em Cnel. Rosales, Laprida e Tres Arroyos. Na 7a, os votos deram uma leve diferença a favor de Cafiero. Somente na $8^{\text {a }}$ seção, La Plata, Cafiero obteve uma amplíssima maioria. Ali venceu por 14.201 votos contra 6.871, demonstrando a capacidade da fração do partido no governo de mobilizar uma quantidade maior de carros e táxis para transportar votantes (ED, 10/7/1988).

\section{Práticas políticas e construção do poder}

$\mathrm{O}$ avanço do menemismo na província de Buenos Aires entre sua chegada na província e o triunfo eleitoral foi interpretado de diversas maneiras pelos contemporâneos. Unidos, a centro-esquerda do partido, atribuiu esse avanço aos defeitos e virtudes da renovação cafierista. Alguns destacaram a incapacidade desta corrente, mais preocupada em autonomizar e democratizar a política interna do que em articular um projeto político e social alternativo ao vigente - e, neste sentido, próximo demais do alfonsinismo. Outros destacaram como positivo que os renovadores não claudicassem diante da possibilidade de restaurar as figuras, as práticas ou o estilo de condução da direção que justificou seu nascimento ${ }^{25}$. Da parte da direita, em compensação, a ênfase caia na soberba dos “jovens turcos”, aos quais Herminio Iglesias

\footnotetext{
Neste sentido, cf. Unidos, el menómeno peronista. № 19, out. 1988. Disponível em: http://www.croquetadigital.com.ar. Entre os artigos reunidos, sobre o conteúdo popular do menemismo, H. Chumbita, "El peronismo según Menem"; um questionamento à visão diádica da sociedade e das benesses do menemismo diante do cafierismo, M. Wainfeld, "¿Patoruzú le ganó a Isidoro?"; sobre a falta de alternativas da renovação no governo e na proximidade do "povo", E. López, "Primeras imágenes del naufragio"; sobre o mesmo tema e o fracasso da estratégia gremial da renovação, A. López e C. Lozano, "Turco que me hiciste mal e sin embargo te quiero"; sobre a coerência da renovação como causa de sua derrota, N. Ivancich, "Desdeño la romanza de los tenores huecos" e, especialmente, V. Palermo, "Entre renovadores y restauradores".
} 
não vacilou em qualificar como "imperadores da derrota” (ED, 12/7/1988). Um seguimento das práticas concretas que derivaram no triunfo da chapa Menem-Duhalde pode lançar maior luz sobre esses resultados.

\section{A cooptação concertada de dirigentes}

A partir de 1985 tornou-se cada vez mais evidente que Menem agia de maneira independente com respeito ao resto da renovação e que, como parte de sua estratégia, propiciou a formação de correntes internas de oposição ao peronismo renovador em diversos distritos ${ }^{26}$. Mas para enfrentar internamente o cafierismo era imprescindível contar com adesões no peronismo bonaerense. Já em abril de 1986 alguns chefes comunais pronunciaram-se a favor de sua candidatura para ser presidente do partido ${ }^{27}$.

Antes das primeiras eleições internas em que FyL participou na província (novembro de 1986), Menem e seu punhado de seguidores procuraram apoios no desmembrado setor que antes havia respondido a Herminio Iglesias ${ }^{28}$. Foi elogiado por Diego Ibáñez, secretário geral de SUPE e presidente do bloco justicialista da Câmara de Deputados da Nação, um anticafierista declarado ${ }^{29}$. Obteve o apoio do ultradireitista Manuel Anchorena, de José Argento, assim como também daqueles que nesse momento eram independentes (mas que em 1983 eram companheiros de rota de Iglesias): José Carmelo Amerise, Juan Taccone e Juan Fernández Vanoli (LN, 10 e 19/7/1986). Em agosto, o próprio Iglesias respaldou Menem e resgatou seu comprometimento com a unidade. De modo que se FyL foi uma cunha que deixou em evidência, mais do que

${ }^{26}$ LN, 1/3/1986; ED, 16/3/1986. Até solicitou apoio dos peronistas de Río Cuarto ao candidato a intendente radical.

27 Eram os intendentes de La Matanza (Federico Russo), Lanús (Manuel Quindimil), Berazategui (Arturo Ramón), Berisso (Carlos Nazar) e Moreno (Héctor Nazar) (ED, 16/4/1986).

${ }^{28}$ Após as eleições de novembro de 1985, a liderança de Iglesias ia chegando ao seu fim. Atrás ficavam os dias em que o ex-intendente de Avellaneda, com o apoio do setor ortodoxo do sindicalismo, conduzia o partido auxiliado por seus homens de confiança e conseguia impor sua autoridade combinando práticas manipulatórias (utilizadas, por exemplo, em instâncias da filiação de 1982) com outras coercitivas (a demonstração do uso da força de seus seguidores no congresso partidário em que resultou designado candidato a governador em 1983). Também era longínqua sua confirmação como autoridade nacional partidária em julho de 1985, quando no congresso de La Pampa assegurou com os votos dos congressistas bonaerenses - que representavam um terço do organismo - sua eleição e a de uma direção que em breve lhe seria adversa. De fato, depois daquelas eleições foi separado de seu cargo como secretário geral do partido, sob alegação da ilegitimidade com que tinha agido na província no último ano. Sobre sua marginalização no PJB cf. Ferrari, 2011. Acerca da cooptação dos herministas disponíveis por parte de Menem, ver ED, 21/7/1986.

${ }^{29}$ A esse respeito, cf. as entrevistas a Carlos Corach e Carlos Grosso, na rede Archivos Orales (RAO) do IGG, UBA. 
nenhuma outra agrupação, a heterogeneidade dos renovadores, operou como força centrípeta dentro do conjunto das dispersas forças da direita peronista bonaerense. Também foi apoiada por alguns membros das 62 Organizações $^{30}$.

Antes das eleições de candidatos a legisladores e autoridades municipais de abril de 1987, é possível registrar uma rede de unidades básicas a partir das quais FyL realizou tarefas de conscientização e recrutamento de eventuais votantes internos. Além disso, a fusão realizada em La Plata para integrar a lista 501 platense levou essa corrente a ficar como parte integrante de uma agrupação maior, conduzida por Eduardo Duhalde.

$\mathrm{O}$ intendente de Lomas de Zamora era um indiscutido renovador da $3^{\mathrm{a}}$ seção eleitoral, que desde que ocorrera a recuperação democrática ia ganhando presença na província e visibilidade nos meios de imprensa provinciais e nacionais ${ }^{31}$. Este advogado de extração gremial, que tinha exercido a política junto com sua atividade imobiliária, era o porta-voz da Liga de Intendentes Peronistas, organizada depois das eleições de 1983 com a finalidade de fechar posições diante da governação radical. Junto com ele estavam nessa Liga seu amigo renovador Julio Carpinetti, os ortodoxos Manuel Quindimil e Federico Russo, intendentes de Lanús e La Matanza, respectivamente, e independentes como Arturo Ramón, de Berazategui. Embora essa associação de vereadores peronistas tivesse como objetivo discutir os problemas que afetavam suas comunas (coparticipação, segurança, moralidade, federalismo), foi um espaço de diálogo entre peronistas de diferentes tendências, onde eram feitas colocações para fora do partido, mas também para o interior. Assim, por exemplo, durante o período de intervenção do PJB prévio à normalização de 1986/87 seus integrantes propuseram que, antes das eleições internas, todos os setores justicialistas deviam chegar a um entendimento. Elaboraram um documento no qual propiciaram a constituição de uma junta interventora e outra eleitoral, que fossem representativas dos diferentes setores internos, e entregaram-no à direção nacional por meio de seu porta-voz (LN, 22/3/1986; ED, 11/1; $6 / 2 / 1986)$. Ou seja, era um espaço no qual se favorecia a unidade. Além disso, Duhalde, que tinha vínculos partidários sólidos com integrantes da direção nacional, assumiu uma atitude desafiante diante dos dirigentes renovadores

\footnotetext{
30 Sobre a relação entre os ramos sindical e político durante o período, cf. Gutiérrez $(2001$; 2003) e Levitzky (2005).

${ }^{31}$ Cf. "Eduardo Duhalde. Intendente de Lomas de Zamora", entrevista de María Esther Gilio. El Periodista, ano 1, n. 13, 8 a 14 de dezembro, 1984, p. 34 e 35.
} 
quando assistiu a duas reuniões partidárias que eles não aprovavam: a plenária de Catamarca e, posteriormente, o congresso partidário realizado em Tucumán, ambos convocados pelo CNJ, encabeçado por Vicente L. Saadi, das quais também participou Menem (ED, 19/9/1986; LN, 13/4, 30/9; 30/10/1986) ${ }^{32}$. E no momento das eleições de abril de 1987 não cortou seu apoio à lista 501, da qual fazia parte FyL, que se reconheceu dentro do espaço de "Unidade e Renovação" fundado por Duhalde e Carpinetti. Foi o único referencial de nível provincial que esteve presente em um ato de encerramento de campanha em La Plata.

A desfeita de Cafiero ao deslocar Duhalde do primeiro lugar da lista de deputados nacionais para o segundo (julho de 1987) foi decisiva para o avanço do menemismo na província. É provável que a decisão de Cafiero tenha guardado relação, mais do que com o argumento que defendia a posição de Luder como constitucionalista (ED, 27/7/1987), com a independência mostrada por Duhalde, que tinha assistido aos congressos nacionais convocados por Saadi, ganhava na 3 a seção e gravitava como porta-voz da Liga de Intendentes. Todos estes elementos introduziam tensões no andaime político cafierista e até mesmo desafiavam-no. Mas as consequências do deslocamento foram piores. Paralisado momentaneamente, o intendente de Lomas de Zamora devotou com decisão suas redes partidárias e sua capacidade organizativa em prol do riojano ${ }^{33}$. Promoveu a consolidação do menemismo em cada um dos distritos da GBA e em La Plata. Na capital provincial, por exemplo, em abril de 1988 dedicou uma jornada completa ao encontro com dirigentes políticos e sindicais da seção Capital no Teatro Lozano, para organizar o minoritário e disperso setor, integrado por três agrupações: Casa de La Rioja, Menem Presidente e Menem Presidente dos Argentinos. No fim do dia, tinha definido a união das expressões do menemismo platense. Mas, além disso, desfilaram pelo lugar os representantes de umas vinte agrupações e de um número não determinado de unidades básicas. Do encontro resultou, também, a convocatória para uma plenária com o fim de deixar constituída uma mesa de condução e um comando eleitoral "integrado por representantes de todos os ramos do movimento" 34 . Seu trabalho como "armador" do menemismo no interior da província foi menos importante, provavelmente porque era

32 Declarações de Duhalde sobre o congresso em ED, 9/11/1986.

33 Entre outros, cf. López Echagüe (2002).

${ }^{34}$ Destacou-se a presença de dirigentes de base, como Juan Bertoletto, Rodolfo Desio e Héctor Dateo, Jorge Versillo, Néstor Tartaglia, Daniel Papasodaro, Martín Sánchez e Rolando Hnatiuk. Também estiveram presentes Juan Carlos Rousselot e Oscar Amosa (ED, 15/5/1988). 
um território que tinha mais afinidade com o governador, mas, sem dúvida, porque a interna seria decidida na GBA e na seção Capital.

A cooptação utilizou também outros mecanismos. Superada a eleição de governador (setembro de 1987), Menem incluiu na representação de La Rioja o conselho nacional partidário, junto com seu irmão Eduardo Menem e seu cunhado Jorge Yoma, os dirigentes bonaerenses Julio Corzo, Alberto Kohan, Juan Carlos Rousselot, Lucía Peroni e Dante Canaglia e Jorge Rachid, de Neuquén (ED, 31/12/1987). Por meio de um distrito que não era o de seu lugar de residência, os bonaerenses alcançavam uma posição expectável no partido e Menem garantia sua adesão.

O efeito multiplicador do menemismo na província de Buenos Aires foi favorecido por incorporações nas quais acreditamos interpretar certa lógica das vantagens da faccionalização, de longa data: alguns dirigentes encabeçavam um desprendimento partidário para adquirir uma posição que se continuassem no tronco principal do partido não teriam adquirido. É provável que este seja o caso do deputado nacional Alberto Pierri. Vindo do partido de La Matanza, sua chegada foi particularmente bem-vinda, uma vez que o intendente municipal Federico Russo - que em abril de 1987 era considerado entre os que aderiam ao menemismo -, transferiu sua adesão para Cafiero quando ele foi eleito governador da província ${ }^{35}$.

Ou seja, a circulação de dirigentes ia em um duplo sentido. Russo não foi o único que fez um realinhamento em sentido contrário (aderindo ao cafierismo). Entre aqueles que inicialmente haviam simpatizado com FyL, também Manuel Quindimil, de Lanús, transferiu sua adesão para Cafiero. E, em La Plata, os conselheiros partidários Luis Lugones, Enrique Cano e Julio Alak, que tinham feito parte da 501 junto com a FyL, voltaram, junto com seu companheiro O. Guida, a alinhar-se atrás de Cafiero (ED, 13/3; 23/5/1988).

\section{A intervenção sobre as condições da eleição}

A postergação do cronograma eleitoral e, sobretudo, a separação da eleição da chapa presidencial da do resto dos cargos partidários, permitiram ao menemismo marcar o ritmo e as condições da eleição. Se com a primeira estratégia ganhou um tempo precioso para montar a rede de lealdades, a segunda permitiu que "a rede de punteros (cabos eleitorais) não se sentisse

35 A reiteração do apoio a Cafiero em ED, 10/3/1988. 
comprometida em dar seu apoio a Cafiero: rompia o aparato partidário horizontalmente" (Ivancich, 2004; 2007, p. 254). Isto foi possível, segundo Ivancich, sob a ameaça de apresentar o peronismo dividido e "entregar" as eleições presidenciais ao radicalismo.

As mensagens do setor menemista sempre foram ambíguas em matéria de permanência no partido. Em fevereiro de 1988, Duhalde advertia que se no processo de eleições internas não imperassem regras de jogo claras e transparentes, restava o recurso de apresentar duas ou mais chapas justicialistas para a eleição de 1989, com o compromisso de apoiar no Colégio Eleitoral aquela que fosse mais votada. E advertia que "seria um erro que o peronismo pagaria muito caro pôr em jogo as estruturas orgânicas do movimento como forma de pressão (...) com o objetivo de torcer a vontade das bases", levando em conta que um dos componentes essenciais da crise argentina era a falta de confiança e de credibilidade nas pessoas (ED, 23/2/1988). Dias depois, Eduardo Menem desmentia qualquer possibilidade de cisão (ED, 26/2/1988). Mas os rumores multiplicaram-se após a notícia de que De la Sota completaria o binômio junto com Cafiero.

Essas advertências cruzadas - que fizeram parte da essência menemista (Vásquez, 2000, p. 12-20)- atuaram como elemento de pressão sobre os cafieristas, que realizaram uma série de concessões para evitar o rompimento. A primeira consistiu em separar as eleições de candidatos presidenciais do resto das candidaturas internas do partido. Apesar de esse setor ser favorável a eleger simultaneamente candidatos a cargos de governo e partidários, provinciais e nacionais, inicialmente cederam em votar "meia chapa", ou seja, as candidaturas da chapa presidencial e as autoridades partidárias (ED, 6 e 13/3/1988). Pouco depois, o próprio Carlos Menem ameaçou procurar a justiça caso não se votasse apenas a chapa presidencial, uma vez que qualificava qualquer outra possibilidade como uma manobra destinada a confundir o eleitorado (ED, 15/3/1988). Em 15 de março de 1988, o conselho do PJB cedeu às suas pretensões. Os argumentos do cafierismo foram claros - e otimistas - no sentido de minar os fundamentos das ameaças de rompimento que "se tornaram públicas pela via de declarações efetuadas por dirigentes menemistas" (ED, 16/3/1988) ${ }^{36}$.

\footnotetext{
${ }^{36}$ Norberto Ivancich (2004; 2007, p. 254), sociólogo comprometido com a renovação peronista, explicou o triunfo de Menem na interna como fruto de uma chantagem: se não se separava a eleição da chapa de candidatos presidenciais da do resto dos candidatos do peronismo, fraturariam o partido, com o que "entregariam" a eleição para a UCR.
} 
A segunda modalidade de intervenção sobre as questões instrumentais foi a postergação da data das eleições. Inicialmente previstas pela Frente Renovadora para maio, foram postergadas de comum acordo para o dia 26 de junho e realizadas, finalmente, em 9 de julho. O motivo era que o setor menemista considerava que os registros eleitorais apresentavam defeitos em vários distritos provinciais - entre eles, a província de Buenos Aires ${ }^{37}$. Independentemente da veracidade dos argumentos, sempre postos em dúvida pelo cafierismo como manobras dilatórias, enquanto eram depurados os registros, o menemismo reforçava suas adesões. $\mathrm{O}$ apoderado do cafierismo, Carlos A. Alvarez, respondia que tinham sido entregues os registros de Salta, Entre Ríos e os da província de Buenos Aires, de modo que os renovadores enfrentavam a ação psicológica do menemismo, que deixava a porta aberta para postergar a eleição com a reserva do art. 29 (ED, 14/6/1988). O próprio Cafiero afirmou que não existiam razões para a postergação, apesar de finalmente ter aceitado a existência de irregularidades e, com isso, a postergação das eleições, declarando que se sentia extorquido pelas ameaças de rompimento do partido (ED, 16/6/1988).

\section{Campanhas eleitorais}

Este aspecto foi fundamental na estratégia de Menem, porque permitiu que se consolidasse no eleitorado cultivando um estilo prezado pelo peronismo, o do personalismo, diante de um Cafiero menos carismático que seu rival, que tendia à despersonalização e sobre quem, além disso, pesava a responsabilidade de ser o governador do "primeiro estado argentino" e o presidente do Conselho Nacional Justicialista. A campanha eleitoral na interna foi empreendida pelo menemismo com grande cuidado, porque proporcionou a oportunidade de realizar uma disputa de dimensão simbólica e apresentar-se como o autêntico peronismo, recuperando a face populista, o contato com as massas, os mitos, as personalidades esquecidas. Além disso, se a cooptação dos dirigentes contribuía para mobilizar aqueles que se encontravam na órbita dos punteros, uma campanha aberta influía nos filiados peronistas não mobilizados clientelarmente pelos integrantes do aparato, esse piso de $60 \%$ de filiados ausentes nas internas.

Um dos argumentos esgrimidos foi o da unidade. Já nas eleições de abril de 1987 os membros da lista 501 de La Plata, da qual participou FyL e que

${ }^{37}$ Os outros distritos nos quais se detectavam irregularidades referentes aos registros eram Salta, Santa Fe, Chaco, Entre Ríos e Jujuy (ED, 1/6/1988). 
teve o apoio de Duhalde, apresentavam-se perante a sociedade com atitudes e argumentos que estavam de acordo com sua denominação, "Unidade e Renovação", e com o estilo político que o peronismo procurava adotar. O respeito pelo companheiro foi posto em evidência com a organização de um ato de desagravo a Carlos Vallejos - secretário geral de ATE La Plata que encabeçava a chapa de senadores provinciais da opositora lista 91-, ante a distribuição de um panfleto que "pretendia modificar o clima de convivência que deve imperar em uma interna partidária” (ED, 6/4/1987). Também foram hábeis ao apropriar-se de frases de Perón, de forte conotação simbólica, que faziam referência a que "não é hora para lutas intestinas (...) do triunfo do Movimento depende o sucesso de cada um"; é preciso "escolher os melhores" e "este é um problema de dirigentes (...) se chegou a hora para que os argentinos superemos diferenças entre tradicionais adversários, como não vamos pensar de maneira preferencial para que a mesma coisa ocorra entre peronistas?" (ED, 25/4/1987). Inclusive sugeriam favorecer "uma renovação de métodos e de pessoas para chegar a uma luta política interna pela ideia, ratificando os princípios da doutrina nacional justicialista" (ED, 25/4/1987; ênfases da autora), um argumento que, embora fizesse parte da linguagem partidária renovadora, tinha sido o leit motiv de Antonio Cafiero (Altamirano, 2004).

Durante a campanha que precedeu a eleição da chapa presidencial peronista, a corrente Menem Presidente potencializou o uso de recursos simbólicos tradicionais do peronismo para disputar o apoio dos filiados.

As campanhas de ambas as correntes internas intensificaram-se a partir do final de abril. Na província de Buenos Aires as zonas mais disputadas foram a GBA - integrada pelas seções $1^{\text {a }}$ e $3^{\mathrm{a}}$ - e La Plata, uma vez que desde o começo os menemistas deram por perdido o interior do distrito.

Desenvolveram-se em um clima enrarecido pelo agravamento da situação econômico-financeira nacional e pela ameaça de levantamento de certos setores das FFAA - que se materializou no levantamento de Aldo Rico no começo do ano. Nesse contexto, o diálogo entre o oficialismo e o presidente do PJ depois das eleições de setembro de 1987 foi fluente. O encontro de Alfonsín com Cafiero para combinar uma agenda que incluía a redistribuição de fundos coparticipáveis, o pacto federal e a eventual reforma constitucional mostravam que esses líderes estavam muito próximos.

Ambos os setores programaram cuidadosamente suas campanhas e fizeram o acordo de não cair em agressões impossíveis de superar. Em todo 
momento, apesar da desqualificação do "outro", os rivais internos foram recuperados como companheiros peronistas, renovadores, enquanto o radicalismo era assinalado como sendo o verdadeiro adversário. Duhalde afirmava que "devemos trabalhar levando em conta que é uma simples eleição interna e, portanto, é preciso preservar a unidade entre os companheiros, evitando insultar aqueles que não compartilham nosso projeto" (ED, 22/4/1988). E Cafiero insistia em que "o verdadeiro adversário não é o companheiro, mas sim os radicais" (ED, 22/4/1988).

A movimentação foi semelhante à que se faz antes de uma eleição geral. As tarefas foram planejadas por circunscrição e por zona. Os membros de ambas as chapas introduziram tópicos próprios de uma campanha aberta, referindo-se à situação nacional, às medidas de governo a serem adotadas caso fossem eleitos, ao perfil dos ministros que seriam nomeados. Contudo, houve uma diferença: enquanto o cafierismo operou mais sobre a direção partidária, o menemismo agiu em contato direto com o filiado e com a cidadania em geral. Cafiero, que em tempos de campanha pela governação tinha protagonizado as caravanas da esperança - à frente das quais percorreu, como se deve lembrar, boa parte da GBA -, como pré-candidato a presidente da República, não empreendeu ações desse tipo. Em compensação, Menem recorreu a elas de modo permanente.

Essas diferenças tornaram-se transparentes em 24 de abril, quando os candidatos coincidiram na zona metropolitana da província, um em La Plata (Cafiero) e o outro em Berisso (Menem) (ED, 20/4/1988). A primeira diferença deu-se na preparação da convocatória. Por meio dos canais partidários oficiais, o cafierismo convocou uma plenária de juntas promotoras de campanha com o objetivo de garantir uma assistência importante e destacada às urnas por meio da mobilização das delegações provinciais. Ao encontro foram convocados apenas os representantes do ramo político (ED, 23 e 24/4/1988). A caravana de Menem, por sua vez, foi organizada por dirigentes políticos de diversas vertentes, mas, sobretudo, por Duhalde, que - como se deve lembrar- após dedicar uma jornada completa à organização da corrente promoveu a fusão do menemismo platense e ajustou os detalhes da mobilização de Menem por Berisso (ED, 23 e 24/4/1988).

De acordo com o que indica a imprensa, no dia 24 de abril cada um dos candidatos mobilizou cerca de 6000 pessoas (ED, 24/4/1988). Cafiero pronunciou um apaixonado discurso no Poliesportivo Platense de Ginás- 
tica e Esgrima ante os delegados das juntas promotoras de campanha de toda a província, que assistiram de maneira orgânica. Enquanto isso, as ruas de Berisso foram transformadas em um espaço de congregação que tornava desnecessários grandes pronunciamentos (ED, 24/4/1988). Menem e Duhalde passearam a bordo de um conversível e mantiveram encontros com dirigentes gremiais das 62 Organizações e da CGT Regional, representantes do ramo feminino e protagonistas do histórico 17 de Outubro, que receberam medalhas comemorativas em um ato de grande emotividade. Em sucessivas paradas, o pré-candidato pronunciava algumas palavras que destacavam o papel do movimento operário como coluna vertebral do peronismo, a necessidade de uma moratória no pagamento da dívida externa para evitar o sacrifício do povo e até anunciava nomeações no gabinete de seu futuro governo, colocando um empresário na pasta de Economia e um trabalhador na de Trabalho (ED, 24/4/1988). Ou seja, enquanto Cafiero se limitava a intervir sobre a direção do partido, Menem expunha-se perante a cidadania, ostentava tradição populista, lembrava a gesta fundacional do movimento e posicionava-se como candidato - mais do que como pré-candidato - presidencial.

Demonstrações como a anterior levaram-no ao topo do ranking de popularidade $^{38}$. Na GBA impactaram com força suas denominadas - com reminiscência das realizadas anteriormente por Cafiero - "caravanas da esperança”. Foi importante a realizada em La Matanza, onde circulou acompanhado por Alberto Pierri e por Alberto Brito Lima, do ultradireitista Comando de Organização (ED, 7/5/1988). A bordo do "menemóvel" (outro eco da campanha de Cafiero como candidato a governador e, também, da visita do papa João Paulo II), as caravanas foram reeditadas em La Plata ( $8^{\mathrm{a}}$ seção) e na $1^{\text {a }}$ seção eleitoral, onde em três dias percorreu San Isidro, Vicente López, San Martín, 3 de Febrero e Morón e, depois, os distritos do oeste, Mercedes, Navarro, Las Heras, Marcos Paz e Gral. Sarmiento e, finalmente, Luján, Gral. Rodríguez, Moreno e Merlo (ED, 11, 14, 15 /5; 11/6/1988). Até meados de junho continuou realizando caravanas pela $3^{\text {a }}$ seção, a de maior número de filiados. Os organizadores promoviam essas mobilizações como um contato direto com o povo, que expressava nas ruas "a decisão das maiorias peronistas de derrotar os aparatos, levantando um novo líder do movimento” (ED,

38 Também fez um grande nhoque em La Boca (ED, 29/5/1988) ou convidou para empanadas, servindo mesas que cobriam duas quadras da rua 32, em La Plata (ED, 7/6/1988). 
14/5/1988). Era nas ruas onde melhor se desenvolvia o governador riojano, que nunca aceitou participar em um debate de ideias, como sugeria Cafiero (ED, 29 e 30/5/1988). Desde esse cenário, mostrava Cafiero, como um homem de aparato, afastado das bases, que renegava do movimento.

O menemismo também mostrou astúcia na "guerra dos cartazes" de campanha. Um caso pontual é o dos cafieristas que empapelaram as principais artérias de La Plata com cartazes de grande ambigüidade, que diziam: "Menem te quiero" e logo abaixo "por eso voto en Cafiero"39. Rapidamente os menemistas cobriram a segunda parte dos cartazes com outros em que apareciam as imagens de Menem e Duhalde, acompanhados de lemas como "Menem-Duhalde. Escolheu bem" ou "O povo já escolheu. Menem presidente. Cafiero governador" (ED, 6/6/1988).

Os comícios de encerramento de campanha foram realizados na Capital Federal e nutridos com contingentes vindos da GBA e de La Plata, fáceis de mobilizar por razões de proximidade geográfica. Cafiero realizou o seu na Praça de Maio, de maneira tradicional, com a participação de alguns músicos populares. Embora a imprensa fale de uma importante participação (imprecisa), as condições climáticas atentaram contra seu sucesso. Alguns dias depois, Menem e Duhalde encerraram sua campanha no estádio do River Plate, em um ato concebido como espetáculo, no qual não faltou um palco giratório desde onde os candidatos falaram para os mais de 60.000 assistentes. No palco, ocupavam um lugar destacado as viúvas dos sindicalistas Vandor, Rucci, Kloosterman, Smith e Alonso, assassinados nos anos 70 (ED, 25/6/1988). Todo um símbolo dos setores da ortodoxia peronista do qual estes renovadores não renegavam.

Entre o encerramento da campanha e a data das eleições nada foi deixado ao acaso. Duhalde ia nos centros de filiação e, no comando eleitoral, reunia-se com fiscais de mesa, fiscais gerais, presidentes de mesa e com os encarregados, para dar-lhes instruções (ED, 27/6/1988). Paralelamente, convocava líderes gremiais. Não perdia ocasião para falar sobre a "rebelião das bases", que queriam recuperar o querido peronismo. A partir de seu setor a política face-a-face tornou-se generalizada: bater nas portas, visitar pessoalmente os indecisos. Toda tarefa era valorizada na hora de conseguir a mobilização dos filiados (ED, 7/7/1988).

39 *N. da T.: "Menem te quero", "por isso voto em Cafiero". 
Os resultados eleitorais compensaram tão febril atividade. Alguns testemunhos dão conta da presença nas eleições daqueles que iam votar depois de "descer de um ônibus de linha" em vez dos meios de transporte financiados pelo partido ${ }^{40}$.

\section{Algumas reflexões}

Desde os tempos das direções paralelas resultantes dos congressos do Odeón (dezembro de 1984) e de Río Hondo (fevereiro de 1985) as divisões do peronismo nunca tinham se manifestado tão claramente quanto durante o período analisado. Os resultados destas internas acabaram com o equilíbrio que até então tinha sido mantido no peronismo e mostraram que a renovação cafierista, apesar do controle dos principais espaços de direção, não havia conseguido firmar-se.

Pouco tempo antes do lançamento de FyL os setores identificados como a ortodoxa direita peronista se colocaram à disposição das aspirações do governador riojano. Dois anos depois, utilizando os critérios de seleção que fez com que toda a renovação respeitasse, Menem Presidente desafiava àqueles que acusava de ser uma elite que queria impor mudanças desde cima e expunham sua fragilidade, acentuada pela deteriorada situação econômico-social do país.

$\mathrm{Na}$ província de Buenos Aires esse deslocamento foi acontecendo ao ritmo das eleições internas. Quando foi feita a convocação para a seleção de autoridades partidárias (16/11/1986), de candidatos a governador e vice $(10 / 1 / 1987)$ e de candidatos a deputados nacionais, legisladores provinciais e autoridades municipais (26/4/1987), um punhado de dirigentes marginalizados pela condução cafierista conseguiu espaços minoritários no conselho partidário bonaerense e fundiu-se oportunamente com outras forças para levar representantes de FyL a posições de direção partidária e a cargos de governo. Diante da convocatória de eleições abertas de 6 de setembro de 1987, essa corrente fechou filas com Cafiero e contribuiu para o seu triunfo como governador, ao mesmo tempo que pôde consagrar alguns poucos candidatos no parlamento, na legislatura e em certas intendências.

Depois de que Carlos Menem foi nomeado vice-presidente do partido, sua corrente assumiu uma estratégia combativa para impor a fórmula

${ }^{40}$ Da entrevista a Benedetti, cit. Um testemunho semelhante em Ollier (2010). 
presidencial. Em primeiro lugar, enfatizou na organização de uma rede de dirigentes, em cuja construção foi central a figura de Eduardo Duhalde, que contribuiu com seu capital político prévio, sua capacidade como armador político e seus vínculos pessoais, promoveu a fusão de agrupações que aderiam ao menemismo, arbitrou conflitos entre líderes, cooptou novos seguidores, ampliou as redes de lealdades. Este dirigente sempre fez menção ao respeito pelo companheiro e sempre invocou a unidade do movimento. Incluía, é claro, o sindicalismo, principalmente as muito fortes 62 Organizações desprezadas pelos seguidores de Cafiero e, em especial, por De la Sota. Segundo, apelou a questões instrumentais (exigências de maior precisão no registro eleitoral, pressão para postergar o cronograma eleitoral) sob ameaça de fratura do partido, tantas vezes comentada quanto negada pelos menemistas. Terceiro, foi realizada uma campanha eleitoral de forte impacto - direto e midiático -, na qual foram utilizadas práticas e foram pronunciadas alocuções breves, próprias de uma eleição aberta, que deram grande popularidade ao candidato. Essa estratégia ofensiva, muito bem armada, derivou na vitória interna do menemismo, que começou tendo uma posição desvantajosa na província.

Os resultados eleitorais mostraram que as concessões feitas pelos membros da direção oficial do partido tinham jogado contra seus próprios interesses: separação da eleição de candidatos presidenciais dos candidatos a outros cargos eletivos, partidários ou extrapartidários, que os eleitores não aparecessem na mesma cédula que os candidatos, que o escrutínio fosse feito em um centro de cômputos. Imbuídos por uma grande confiança nas adesões internas, desperdiçaram suas possibilidades de controle.

A derrota foi dramática para Cafiero. Significou a perda da liderança real no partido e eclipsou seu governo. Para os cafieristas - e para boa parte da sociedade -, voltava o peronismo da derrota. Nas filas menemistas era comemorado o triunfo do movimento sobre a tirania, primeiro de Iglesias e, depois, da cúpula partidária elitista, eleitoralista e exclusivista que influiu sobre Cafiero (ED, 13/7/1988).

\section{Referências bibliográficas}

ALTAMIRANO, Carlos. 2004. "La lucha por la idea: el proyecto de la renovación peronista”. In: NOVARO, Marcos \& PALERMO, Vicente (eds.). La historia reciente: Argentina en democracia. Buenos Aires: Edhasa. 
ARIAS, Fernanda. 2004. "Institucionalización partidaria en el justicialismo: la corriente renovadora”. Revista de la SAAP, v. 1, n. 3, p. 489-513.

BOURDIEU, Pierre. 1991. El sentido práctico. Madri: Taurus.

CAFIERO, Antonio. 2007. Razones para ser peronista. Buenos Aires, Copppal/Sudamericana.

FERRARI, Marcela. 2011. "El difícil camino dela normalización en el peronismo boanerense”. In: FABRIS, Mariano \& TORTORELLA, Roberto (eds.). Democracia en reconstrucción: mosaico histórico de los años ochenta. Mar del Plata: EUDEM.

.2010. "Hacia la victoria: la organización del peronismo bonaerense de cara a las elecciones de 1987". Trabalho apresentado na VIII Jornada do Departamento de História, UNMdP.

GERCHUNOFF, Pablo \& TORRE, Juan Carlos. 1996. "La política de liberalización económica en la administración de Menem”. Desarrollo Económico, n. 143, p. 77-112

GOUARNALUSSE, Juan Manuel. 2011. "Interpretaciones del consenso popular a las reformas neoliberales y al gobierno de Menem". PolHis. Boletín bibliográfico electrónico, n. 7. Disponível em: http://www. historiapolitica.com/boletin.

GUTIÉRREZ, Ricardo. 2001. “La desindicalización del peronismo y cambio organizativo en el peronismo argentino, 1982-1995”. Política y Gestión, n. 2, p. 93-112.

. 2003. "Entre movimiento y partido: un análisis de las transformaciones organizativas del peronismo (1983-1995)”. Política y Gestión, n. 5, p. 27-76.

IVANCICH, Norberto. 2004. "La institucionalización del Peronismo antes de Menem”. Revista Argentina reciente (Ideología y política contemporáneas), n. 2, p. 7-46.

IVANCICH, Norberto. 2007. Escritos peronistas. Buenos Aires: Sudamericana/COPPPAL.

LEVITSKY, Steven. 2005. La transformación del justicialismo: del partido sindical al partido clientelista, 1983-1999. Buenos Aires: Siglo XXI.

LÓPEZ ECHAGÜE, Hernán. 2002. El otro: Eduardo Duhalde, una biografía política. $2^{\mathrm{a}}$ ed. Buenos Aires: Norma.

McADAM, Andrew. 1996. Cafiero: el renovador. Buenos Aires: Corregidor. MORA y ARAUJO, Manuel. 1995. “De Perón a Menem: una historia del 
peronismo". Peronismo y menemismo: avatares del populismo en la Argentina. Buenos Aires: El Cielo por Asalto.

NOVARO, Marcos. 1994. Pilotos de tormenta: crisis de representación y personalización de la política en Argentina (1989-1993). Buenos Aires: Letra Buena.

.2006. Historia de la Argentina contemporánea. De Perón a Kirchner. Buenos Aires: Edhasa.

.2009. Argentina en el fin de siglo: democracia, mercado y nación (1983-2001). Buenos Aires: Paidós.

NUN, José. 1995. "Populismo, representación y menemismo". Peronismo y Menemismo. Buenos Aires: Ediciones El Cielo por Asalto.

OLLIER, María Matilde. 2010. Atrapada sin salida: Buenos Aires en la política nacional (1916-2007). Buenos Aires: UNSAM.

OSTIGUY, Pierre. 1997. "Peronismo y antiperonismo: bases socioculturales de la identidad política en la Argentina”. Revista de Ciencias Sociales, n. 6, p. 133-215.

PALERMO, Vicente \& NOVARO, Marcos. 1996. Política y poder en el gobierno de Menem. Buenos Aires: Norma.

PORTANTIERO, Juan Carlos. 1995. "Menemismo y peronismo: continuidad y ruptura”. Peronismo y Menemismo. Buenos Aires: Ediciones El Cielo por Asalto.

REVEL, Jacques. (dir.). 1996. Jeux d'échelles: la microanalyse à l'expérience. Paris: Éditions de l'EHESS, Gallimard, Seuil.

VÁZQUEZ, Luciana. 2000. La novela de Menem: ensayo sobre la década incorregible. Buenos Aires: Sudamericana.

\section{Resumo}

A vitória de Carlos Menem no processo interno do partido peronista para escolha do candidato presidencial possibilita entender como uma seleção orientada por princípios democráticos e que, segundo projeções de alguns "renovadores", tinha que resultar na substituição definitiva dos elementos tradicionais do partido, acabou na restauração destes. Portanto, reconstruímos o avanço progressivo de Menem na provincial de Buenos Aires - o bastião peronista - entre janeiro de 1986 e julho de 1988. Resumimos o desempenho obtido nas eleições para a escolha de autoridades e candidatos a cargos governamentais. Também abordamos as razões para esse avanço eleitoral, enfatizando práticas e atores políticos em termos de: (a) a cooptação concertada de lideranças, que 
resultou na construção de um alicerce político capaz de mobilizar a adesão de membros de base, (b) o uso instrumental de aspectos formais inerentes ao processo eleitoral e (c) a campanha pré-eleitoral, que apresentou o "menemismo" como o autêntico peronismo popular, personalista, em contato com as massas, capaz de reivindicar seus mitos - com impacto positivo sobre os filiados em tempos de crise social e política profunda. Essa crise foi atribuída ao governo nacional, ao qual o governador da província de Buenos Aires - seu principal oponente - era considerado demasiado próximo.

Palavras-chave: Argentina; Peronismo; Menemismo; PJ; Província de Buenos Aires

\section{Abstract}

The victory of Carlos Menem in the Peronist party's internal process to choose its presidential candidate allows understanding how a selection guided by democratic principles - which, according to projections by some "renovadores" had to derive in the definitive displacement of the party's traditional elements - ended in their restoration. Therefore, we reconstruct the progressive advance of Menem in the province of Buenos Aires - the Peronist stronghold - between January 1986 and July 1988. We summarize the performance obtained in the elections to choose authorities and candidates for governmental positions. We also approach the reasons for this electoral advancement, emphasizing political actors and political practices regarding: (a) concerted co-opting of leadership that resulted in the construction of a political foundation capable of mobilizing the adhesion of the grassroots members; (b) instrumental use of formal aspects inherent in the electoral process; and (c) the pre-election campaign, which portrayed a representation of the "Menemism" as the authentic Peronism - popular, personalistic, in contact with the masses, able to claim their myths - which had a positive impact on membership in times of deep social and political crisis. That crisis was attributed to the national government, to which the governor of the province of Buenos Aires - the main opponent - was considered too close.

Key words: Argentina; Peronism; Menemism; PJ; Province of Buenos Aires

Recebido em 9 de novembro de 2011.

Aprovado em 11 de fevereiro de 2012. 